\title{
Pyramidal cells in V1 of African rodents are bigger, more branched and more spiny than those in primates
}

\author{
Guy N. Elston ${ }^{1 *}$ and Paul Manger ${ }^{2}$ \\ ${ }^{1}$ Centre for Cognitive Neuroscience, Sunshine Coast, QLD, Australia \\ ${ }^{2}$ School of Anatomical Sciences, Faculty of Health Sciences, University of the Witwatersrand, Johannesburg, South Africa
}

\author{
Edited by: \\ Alfonso Fairén, University Miguel \\ Hernandez, Spain \\ Reviewed by: \\ Yoland Smith, Emory University, \\ USA \\ Alfonso Fairén, University Miguel \\ Hernandez, Spain \\ Alino Martinez-Marcos, Universidad \\ de Castilla, Spain \\ *Correspondence: \\ Guy N. Elston, Centre for Cognitive \\ Neuroscience, 60b Duke Rd, \\ Doonan, Sunshine Coast, \\ QLD 4562, Australia \\ e-mail: guyelston@yahoo.com
}

Pyramidal cells are characterized by markedly different sized dendritic trees, branching patterns, and spine density across the cortical mantle. Moreover, pyramidal cells have been shown to differ in structure among homologous cortical areas in different species; however, most of these studies have been conducted in primates. Whilst pyramidal cells have been quantified in a few cortical areas in some other species there are, as yet, no uniform comparative data on pyramidal cell structure in a homologous cortical area among species in different Orders. Here we studied layer III pyramidal cells in V1 of three species of rodents, the greater cane rat, highveld gerbil, and four-striped mouse, by the same methodology used to sample data from layer III pyramidal cells in primates. The data reveal markedly different trends between rodents and primates: there is an appreciable increase in the size, branching complexity, and number of spines in the dendritic trees of pyramidal cells with increasing size of $\mathrm{V} 1$ in the brain in rodents, whereas there is relatively little difference in primates. Moreover, pyramidal cells in rodents are larger, more branched and more spinous than those in primates. For example, the dendritic trees of pyramidal cells in V1 of the adult cane rat are nearly three times larger, and have more than 10 times the number of spines in their basal dendritic trees, than those in $\mathrm{V} 1$ of the adult macaque (7900 and 600, respectively), which has a V1 40 times the size that of the cane rat. It remains to be determined to what extent these differences may result from development or reflect evolutionary and/or processing specializations.

Keywords: striate, cortex, dendrite, spine, Lucifer yellow

\section{INTRODUCTION}

Studies in primates have revealed marked differences in pyramidal cell structure among different cortical areas (Lund et al., 1993; Elston, 2002, 2003a; Jacobs and Scheibel, 2002; Bianchi et al., 2012). Cells tend to become larger, more branched, and more spiny with progression through cortical areas associated with primary sensory, sensory association, and executive function (see Elston, 2002, 2003a; Jacobs and Scheibel, 2002; Spruston, 2008; Defelipe, 2011; for reviews). The extent of these interspecies differences varies according to the cortical area studied. For example, there is relatively little difference in the size, branching structure, and number of spines (putative excitatory inputs) in the dendritic trees of pyramidal cells in V1 among primates, whereas cells in the granular prefrontal cortex (gPFC) are progressively larger, more branched and more spinous the larger the gPFC (Elston et al., 2006b). Those in human gPFC are, on average, 23-fold more spinous than those in V1 of the macaque; however, it remains to be determined to what extent pyramidal cells may differ among cortical areas in other non-primate mammalian species.

Quantification of pyramidal cells in rodents has also revealed regional specialization in the size, branching structure, and spine density of their dendritic trees. Those in the mouse have been shown to differ among visual, motor and somatosensory cortex (Ballesteros-Yáñez et al., 2006; Benavides-Piccione et al., 2006). In the South American rodent, the cutia, as in primates, cells become larger, more branched, and more spinous with increasing distance from primary visual cortex (Elston et al., 2006c); however, the extent of these differences remain unknown.

Neurons in VI of rodents show orientation preference (Tiao and Blakemore, 1976; Mangini and Pearlman, 1980; Metin et al., 1988; Girman et al., 1999; Schuett et al., 2002; Van Hooser et al., 2005); but, rodent V1 lacks the orientation maps and ocular dominance columns typically associated with primate V1 (e.g., Hubel and Wiesel, 1968; Van Hooser et al., 2005). Furthermore, rodents, while having distinct visuotopic maps, are thought to have fewer clearly differentiated visual cortical areas than primates and have a substantially smaller V1 than primates (Felleman and Van Essen, 1991; Rosa and Krubitzer, 1999; Van Hooser et al., 2005). Variability in the neuronal composition of V1 has also been reported among rodents (Campi et al., 2011). Thus, the question becomes, what, if any, specializations in cortical microcircuitry underpin the differences in visual processing in rodents and primates, and how do they relate to neuronal composition and brain size?

Here we quantified layer III pyramidal cell structure in V1 of the greater cane rat, the bushveld gerbil and the four-striped mouse and compared them with previously published data sampled from the baboon, macaque monkey, vervet monkey, owl monkey, marmoset, galago, and tree shrew. We found that, 
irrespective of brain size, pyramidal cells in V1 of rodents are larger, more branched and more spinous than those in primates.

\section{METHODS}

Three African rodent species, including the greater cane rat (Thryonomys swinderianus), the bushveld gerbil (Tatera branstii), and the four-striped mouse (Rhabdomys pumilio) were included for study. The rodents used in the present study were caught from wild populations in South Africa with permission and supervision from the appropriate wildlife directorates. All animals ( 5 cane rat, 5 striped mice, 6 gerbil) were treated and used according to the guidelines of the University of the Witwatersrand Animal Ethics Committee, which parallel those of the NIH for the care and use of animals in scientific experimentation. Although the ages of the animals is not known, the body mass and physical development indicated that they were sexually mature adults. Animals were sedated with an I.M. injection of ketamine hydrochloride $(40 \mathrm{mg} / \mathrm{kg})$ and xylazine hydrochloride $(4 \mathrm{mg} / \mathrm{kg})$ and overdosed by I.P. injection of sodium pentobarbital $(100 \mathrm{mg} / \mathrm{kg})$.

Methodology used in the present investigation was exactly the same as used in our previous cell injection studies. Animals were perfused transcardially with phosphate buffered saline (0.95\% saline in $0.1 \mathrm{M}$ phosphate buffer [PB; $\mathrm{pH} 7.2]$ ) then paraformaldehyde ( $4 \%$ in $\mathrm{PB})$. The brains were removed and the right hemispheres were flat-mounted (see Elston and Rosa, 1997, for details). The flattened hemispheres were left overnight in $4 \%$ paraformaldehyde in $0.1 \mathrm{M} \mathrm{PB}$ at $4^{\circ} \mathrm{C}$. Alternate serial 250 and $50 \mu \mathrm{m}$ sections were then cut tangential to the cortical surface with the aid of a Vibratome. The $50 \mu \mathrm{m}$ tangential sections were processed for cytochrome oxidase according to the WongRiley method (Wong-Riley, 1979) to reveal the size and location of V1 and other primary cortical areas (Figure 1). Other tangential sections were pre-labeled with 4,6 diamidino-2-phenylindole $\left(10^{-5} \mathrm{~mol} / \mathrm{L}\right.$, D9542, Sigma, USA) for approximately $10 \mathrm{~min}$ at room temperature. These sections were then mounted into a perspex chamber on a fixed stage fluorescence microscope (Zeiss Axioskop II Plus) and individual cells were injected with Lucifer Yellow (LY; L-0259, Sigma: $8 \%$ in $0.1 \mathrm{M}$ Tris buffer, pH 7.4).

Intracellular injection was by continuous negative current. Once approximately 50 cells had been injected in each slice, the sections were processed with anti-LY (1:400 000) in stock solution ( $2 \%$ bovine serum albumin [Sigma A3425], 1\% Triton $\mathrm{X}-100$ \{BDH 30632$\}, 5 \%$ sucrose in $0.1 \mathrm{~mol} / \mathrm{l} \mathrm{PB}$ ) for 5 days at room temperature. 3,3'-diaminobenzidine (DAB; Sigma D 8001) was used as the chromogen (Figure 2) (see Elston et al., 1997, for details). Three hundred and twenty pyramidal neurons were injected in the present study. Two hundred and thirty-three of these cells were included for analyses as they had an unambiguous apical dendrite, issuing from the upper cell body and projecting directly toward the viewer, were well filled, and had their entire basal dendritic trees contained within the slice (108 cells in the cane rat, 61 cells in the gerbil, and 62 cells in the striped mouse). When viewed in the tangential plane the basal dendritic trees of pyramidal cells have a roughly spherical dendritic tree (with some variation) as opposed to the pyramid shape observed in transverse sections. The apical dendrite is observed at low and intermediate power in tangential sections as a black dot over the cell body, due to the extra depth of DAB precipitate in the issuing dendrite as compared with the surrounding cell body (see Figures 2A,B). Moreover, the trajectory of the apical dendrite can be viewed at high power by changing the plane of focus, as can its diameter compared with the basal dendrites issuing from the under side of the cell body. Only neurons that we could establish had their cell bodies located at the base of layer III were included for analyses (e.g., see Figure 3 of Elston and Rosa, 1997). Moreover, we only included cells from the cases in which we injected pyramidal cells in the central 30 degrees of the visual field to minimize any potential confound attributable to intra-areal variation in pyramidal cell structure in V1 according to visuotopy (e.g., Freire et al., 2010).

Pyramidal cells were drawn with the aid of a Zeiss Axioskop 40 equipped with a camera lucida. Dendritic tree size (the area contained within a polygon joining the outermost distal tips of the basal dendrites) and somal size were determined in 2-dimensions with the aid of NIH-Image software (NIH, Bethesda, US) (e.g., Elston and Rosa, 1997). Branching patterns were determined by performing a Sholl analysis on the 2D drawings of cells (e.g., Sholl, 1953). Spines were drawn along the entire dendrite from the cell body to the distal tip of twenty different dendrites in each species while viewing the cells under a $\times 100$ oil objective, changing focus through the depth of the tissue. Spine density was determined by counting the number of spines per $10 \mu \mathrm{m}$ length of dendrite as a function of distance from the cell body (e.g., Eayrs and Goodhead, 1959; Valverde, 1967). An estimate of the total number of spines found in the basal dendritic tree of the "average" pyramidal cell in each cortical area was calculated by multiplying the average number of spines in each successive portion of dendrite by the average number of branches for the corresponding region, over the entire dendritic tree (see Figure 2 of Elston, 2001).

Statistical analysis of the dendritic tree size, branching structure, spine density, and cell body size was performed with SPSS, as per our previous studies (e.g., Elston et al., 2005a,b,c,d,e). In particular, One-Way ANOVAS were applied for dendritic tree size and cell body size, repeated-measures ANOVAS were applied to branching complexity and spine density. Tests for differences in slopes and elevations of plots of the dendritic tree size, branching structure, spine density, and cell body size of the present data sampled in rodents and those data previously sampled from primates (Elston and Rosa, 1997, 1998; Elston et al., 1999, 2005a,b,c,d,e, 2006a; Elston, 2003b) was performed with SMATR software (version 2.0) as per Warton et al. (2006).

\section{RESULTS}

The primary visual area was readily identified in "flat-mounts" prepared from the cortical hemispheres and processed for cytochrome oxidase (Figure 1). The absolute size of V1 in which we injected neurons in all species included for study was quantified. All analyses were performed on the left hemisphere. We found that $\mathrm{V} 1$ in the greater cane rat $\left(44.09 \mathrm{~mm}^{2}\right)$ was larger than that in the bushveld gerbil $\left(14.63 \mathrm{~mm}^{2}\right)$, which was larger than that in the four-striped mouse $\left(11.58 \mathrm{~mm}^{2}\right)$. 

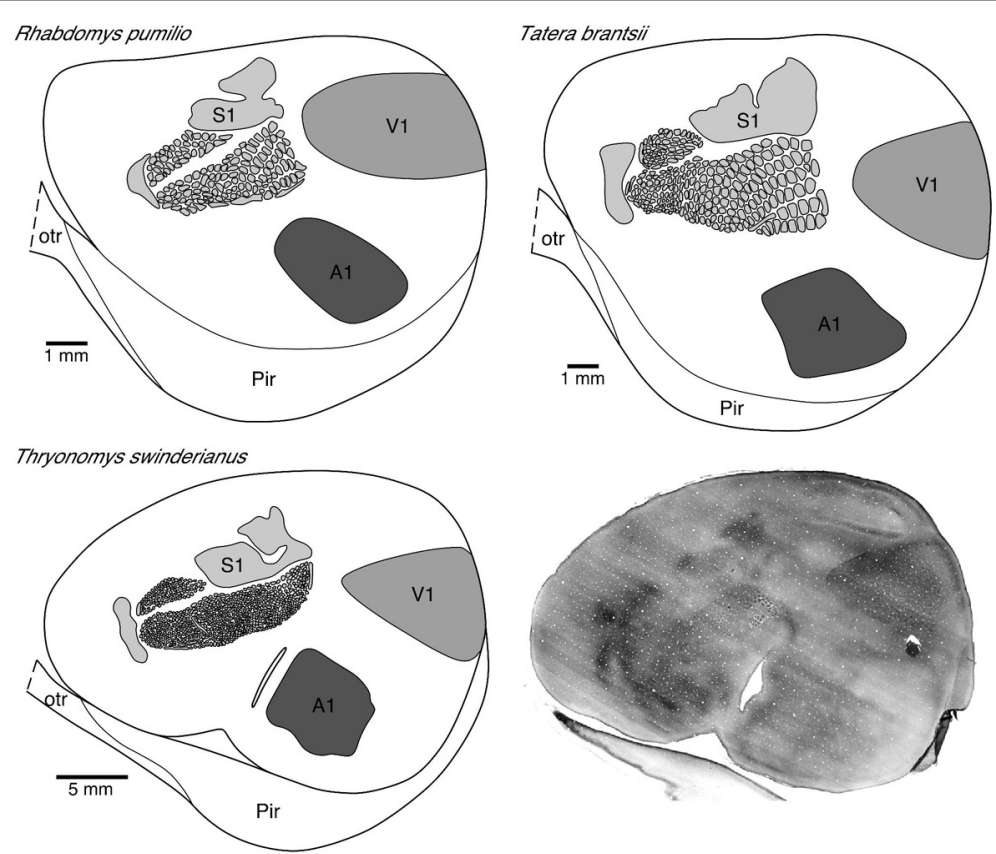

FIGURE 1 | Photomicrograph (bottom right) of a tangential section cut from a "flat-mount" preparation of the entire left hemisphere of the greater cane rat that was processed for cytochrome oxidase reactivity.
Note the easily distinguishable V1 located in the dorsocaudal region with sharply delineated boundaries. Note also the barrels in the primary somatosensory cortex.

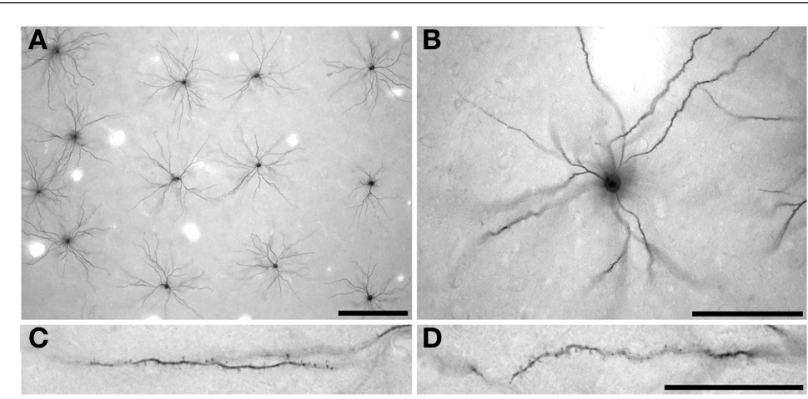

FIGURE 2 | Low- (A) intermediate- (B) and high- (C,D) power photomicrographs of layer III pyramidal cells in primary visual cortex of the greater cane rat (Thryonomys swinderianus) that were injected with Lucifer Yellow and processed for a DAB

(3,3'-diaminobenzidine) reaction product. Cells were injected in a grid-like pattern (A), with each cell being sufficiently spaced from other to avoid cluttering of dendrites (B). The apical dendrite is observed at low and intermediate power in tangential sections (A,B, respectively) as a black dot over the cell body, due to the extra depth of DAB precipitate in the issuing process as compared with the surrounding cell body. (C) and (D) indicate the spine density along the basal dendrites of the layer III pyramidal cells, where the cell body is to the right and the distal tips of the dendrites to the left. Scale bar in (A) $=250 \mu \mathrm{m}$, scale bar in (B) $=100 \mu \mathrm{m}$, and the scale bar in (D) $=50 \mu \mathrm{m}$ and applies to (C) and (D)

\section{BASAL DENDRITIC TREE SIZE}

The basal dendritic trees of layer III pyramidal cells in the greater cane rat $\left(n=108\right.$, mean $\pm S D: 123.15 \pm 24.90 \times 10^{3}$ $\left.\mathrm{mm}^{2}\right)$ were larger than those in the bushveld gerbil $(n=61$, $\left.63.13 \pm 16.28 \times 103 \mathrm{~mm}^{2}\right)$ which, in turn, were larger than those in the four-striped mouse Figure $3\left(n=62,38.55 \pm 12.80 \times 10^{3}\right.$ $\mathrm{mm}^{2}$; Figure 3). One-Way ANOVAs revealed these differences to be significant $\left[F_{(2)}=393.52, p<0.001\right]$. Post-hoc Scheffe tests revealed significant differences among all three species $(p<$ $0.001)$.

\section{COMPLEXITY OF THE BASAL DENDRITIC TREES}

Plots of the results of Sholl analysis in which we counted the number of dendritic intersections in successive concentric circles with radii of $25 \mu \mathrm{m}$ increments revealed that the peak branching density in the basal dendritic trees of layer III pyramidal cells in the greater cane rat (mean \pm SE: $21.99 \pm 5.77$ ) was greater than that in the bushveld gerbil (17.43 \pm 4.12 ), which, in turn, was greater than that in the four-striped mouse $(15.26 \pm 4.05$; Figure 3$)$. A repeated measures ANOVA revealed a significant difference in the complexity of the basal dendritic trees between animals $\left[F_{(2,228)}=167.66, p<0.001\right]$. Post-hoc Scheffe tests revealed all species comparisons to be significantly different.

\section{SPINE DENSITIES OF THE BASAL DENDRITES}

A total of 6484 spines were drawn and tallied. As reported previously (see Elston and DeFelipe, 2002, for review), the spine density along the basal dendrites varied as a function of distance from the cell body to the distal tips. The peak spine density in the basal dendritic trees of layer III pyramidal cells in the greater cane rat $(n=10$; mean \pm SE: $26.4 \pm 3.66)$ was less than that in the bushveld gerbil $(n=2 ; 31.0 \pm 3.03)$, which was 


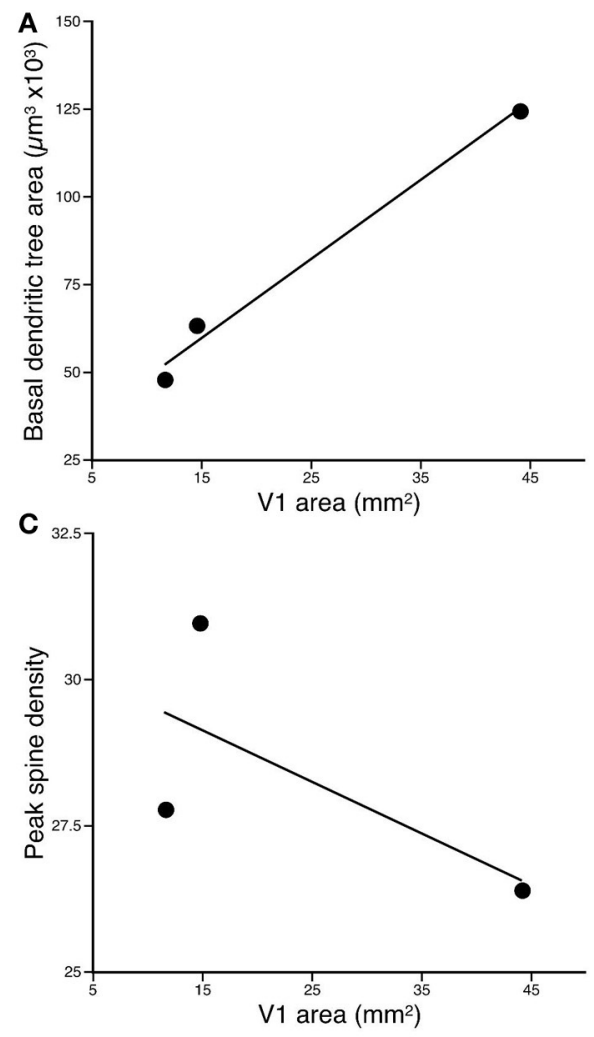

FIGURE 3 | Plots of (A) the size, (B) peak branching complexity, and (C) peak spine density, vs. the size of $\mathrm{V} 1$ of the basal dendritic trees of layer III pyramidal neurons sampled in the primary visual area of the Cane Rat, Bushvelt Gerbil, and Striped Mouse. (D) Plots of cell body size of layer III pyramidal neurons vs. the size of V1. The size of the dendritic trees (in the tangential plane) was determined by calculating the area contained within a convex hull, which joined the outermost distal dendrites. The branching complexity was determined by counting the number of intersections of the basal dendrites with a series of concentric circles of
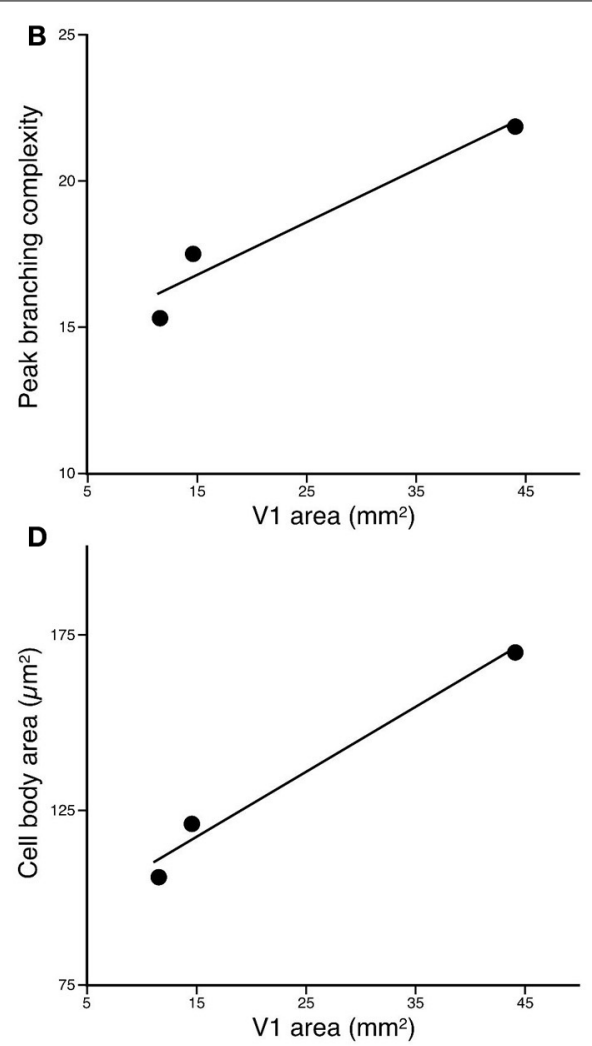

progressively larger diameter (Sholl analysis). The peak branching complexity was the greatest value obtained in each species. Spine density was calculated by drawing horizontally-projecting basal dendrites of different cells in each case at high power ( $\times 100$ oil immersion lens) and counting the number of spines per $10 \mu \mathrm{m}$ interval progressing along the dendrite from the cell body to the distal tips of the dendrite. The peak spine density was the greatest value obtained. Cell body size was determined at high power $(\times 100$ oil immersion lens) by tracing around the outer extent of the cell body while focusing through the depth of the soma. greater than that in the four-striped mouse $(n=10 ; 27.9 \pm 1.81$; Figure 3). A repeated measures ANOVA revealed a significant difference in the spine density between animals $\left[F_{(2,19)}=10.18\right.$, $p=0.001]$. Post-hoc Scheffe tests revealed all species comparisons to be significantly different.

By combining data from the Sholl analyses and spine density counts we calculated an estimate of the total number of dendritic spines in the basal dendritic tree of the "average" layer III pyramidal neuron in V1 of each species. The total number of spines in the basal dendritic trees of layer III pyramidal cells in the greater cane rat (7903) was greater than that in the bushveld gerbil (4316), which, in turn, was greater than that in the four-striped mouse (2141).

\section{CELL BODIES}

The cell bodies of layer III pyramidal cells in the greater cane rat (mean $\pm S D: n=108,170.71 \pm 19.84 \mathrm{~mm}^{2}$ ) were larger than those in the bushveld gerbil at $\left(n=61,121.36 \pm 23.43 \mathrm{~mm}^{2}\right)$, which, in turn, were larger than those in the four-striped mouse Figure 3. $\left(n=62,107.07 \pm 15.86 \mathrm{~mm}^{2}\right.$; Figure 3). One-Way
ANOVAs revealed these differences to be significant $\left[F_{(2)}=\right.$ 239.75, $p<0.001]$. Post-hoc Scheffe tests revealed significant differences among all three species $(p<0.001)$.

\section{DISCUSSION}

Here we studied the structure of layer III pyramidal cells in the primary visual cortex of three African rodents, the greater cane rat, the bushveld gerbil, and the four-striped mouse. We present four main findings: (1) the absolute size of the cerebral cortex occupied by V1 differs up to 4-fold among the three species; (2) there are differences in the size, branching structure, spine density, and total number of spines in the basal dendritic trees of layer III pyramidal cells in V1; (3) the spine density may vary independently of the size and branching structure of the dendritic trees among species; and (4) there is a trend between the size and number of spines in the dendritic trees of pyramidal cells and the size of V1 such that the larger V1 the larger and more spinous are the cells.

Comparison of these data obtained from African rodents with those sampled by the same methodology from V1 of other species 
such as the South American rodent cutia (Elston et al., 2006c), the archontan tree shrew (Elston et al., 2005c), and primates (galago, Elston et al., 2005b; marmoset, Elston et al., 1999; owl monkey, Elston, 2003b; vervet monkey, Elston et al., 2005d; macaque monkey, Elston and Rosa, 1997, 1998; and baboon, Elston et al., 2005e) reveal marked differences in the neuron structure and brain size between primate and rodent species (Table 1, Figure 4). Whereas in rodents the basal dendritic trees of pyramidal cells are increasingly larger in species in which V1 is increasingly larger, there is relatively little difference in the basal dendritic tree size of pyramidal cells in V1 in primates. Moreover, in rodents pyramidal cells are increasingly more spinous and branched in species in which $\mathrm{V} 1$ is increasingly larger in size, whereas there is relatively little difference in the number of spines and branches in pyramidal cells in V1 in primates. Possible developmental and evolutionary influences are discussed below.

\section{DEVELOPMENTAL INFLUENCES ON THE MATURE PYRAMIDAL CELL PHENOTYPE}

Developmental studies in the macaque monkey reveal that the dendritic trees of layer III pyramidal cells at birth are larger than those observed in the adult four-striped mouse and bushveld gerbil, but then become smaller during maturation into adulthood (Elston et al., 2010). In addition, pyramidal cells in V1 of the 3 $1 / 2$ month old macaque monkey, the time of peak synaptic exuberance (Rakic et al., 1986; Bourgeois and Rakic, 1993; Bourgeois et al., 1994), are considerably more spinous than those in the adult four-striped mouse and bushveld gerbil (Elston et al., 2010). It is natural to ask then whether the differences observed in pyramidal cell structure in V1 of the mature brain of rodents and primates may arise from different growth profiles. While any such differences in the growth profile of pyramidal cells may conceivably account for the differences reported in V1 of the adult macaque monkey and the four-striped mouse, bushveld gerbil, and cutia, they cannot account for the differences observed between the macaque monkey and the greater cane rat. The basal dendritic trees of layer III pyramidal cells in the adult greater cane rat are more than twice the size $\left(122.85 \times 10^{3} \mu \mathrm{m}^{2}\right)$ and approximately twice as spinous (7903 spines) as the largest, most spiny cells observed in the macaque during development $\left(53.93 \times 10^{3}\right.$ $\mu \mathrm{m}^{2}$ and 3900 spines, Elston et al., 2010). The basal dendritic trees of layer III pyramidal cells in the adult gerbil are larger than those observed in the macaque at any age. Furthermore, the basal dendritic trees of layer III pyramidal cells in V1 of the adult greater cane rat, gerbil, and striped mouse are larger than those observed in V1 of the developing and adult marmoset monkey (Oga et al., 2013) Thus, while some of the differences in pyramidal cell structure reported here between adult rodents and primates may be attributable to different growth profiles, they cannot be fully accounted for by development alone.

\section{PHYLOGENETIC DIFFERENCES IN THE MATURE PYRAMIDAL CELL PHENOTYPE}

The difference in the relationship in rodents and primates between the size of pyramidal cells and the size of V1 could hardly be more dramatic (Figure 4). Statistical analyses revealed significant differences in the slopes and elevations of the regressions between rodents and primates for all parameters tested (Figure 5;

Table 1 | Data on the size of the brain and V1, and the size, branching complexity, spine density, and total number of spines in the dendritic trees of layer III pyramidal cells in species included in the present investigation.

\begin{tabular}{|c|c|c|c|c|c|c|c|}
\hline Species & $\begin{array}{c}\text { Brain } \\
\text { mass }(g)\end{array}$ & $\begin{array}{c}\text { Area of } \\
\mathrm{V} 1\left(\mathrm{~mm}^{2}\right)\end{array}$ & $\begin{array}{c}\text { Number of cells } \\
\text { included in analyses }\end{array}$ & $\begin{array}{l}\text { Basal dendritic } \\
\text { tree area }\left(\mu \mathbf{m}^{2}\right)\end{array}$ & $\begin{array}{l}\text { Peak branching } \\
\text { complexity }\end{array}$ & $\begin{array}{l}\text { Peak spine } \\
\text { density }\end{array}$ & $\begin{array}{c}\text { Total number } \\
\text { of spines }\end{array}$ \\
\hline Striped mouse & $0.67^{a}$ & $11.58^{a}$ & $62^{a}$ & $48.5^{\mathrm{a}}$ & $15.3^{a}$ & $27.9^{a}$ & $2141^{a}$ \\
\hline Highveld gerbil & $1.61^{\mathrm{a}}$ & $14.63^{a}$ & $61^{a}$ & $63.3^{a}$ & $17.5^{\mathrm{a}}$ & $31.0^{a}$ & $4316^{a}$ \\
\hline Cane rat & $12.9^{a}$ & $44.09^{a}$ & $108^{a}$ & $124.4^{a}$ & $21.9^{a}$ & $24.6^{a}$ & $7903^{a}$ \\
\hline Cutia & $19.45^{b}$ & $14.07^{b}$ & $90^{b}$ & $98.3^{b}$ & $21.6^{b}$ & $11.9^{b}$ & $2524^{b}$ \\
\hline Tree shrew & $3.2^{\mathrm{c}}$ & $30.85^{d}$ & $50^{d}$ & $63.4^{d}$ & 22.8 & 11.1 & $1507^{d}$ \\
\hline Galago & $10.3^{c}$ & $343^{e}$ & $45^{e}$ & $48.4^{\mathrm{e}}$ & $18.0^{\mathrm{e}}$ & $6.3^{e}$ & $556^{e}$ \\
\hline Marmoset & $7.7^{\mathrm{c}}$ & $341^{f}$ & $25^{f}$ & $30.6^{f}$ & $15.9^{f}$ & $7.7^{f}$ & $699^{f}$ \\
\hline Owl monkey & $17.1^{\mathrm{c}}$ & $400^{9}$ & $22^{g}$ & $34.4^{g}$ & $16.9^{9}$ & $9.9^{9}$ & $773^{9}$ \\
\hline Macaque monkey & $70.8^{c}$ & $1866^{h}$ & $213^{h}$ & $43.6^{h}$ & $16.6^{h}$ & $6.9^{h}$ & $734^{h}$ \\
\hline Vervet monkey & $72.6^{c}$ & $2156^{i}$ & $81^{i}$ & $44.3^{\mathrm{i}}$ & $18.5^{\mathrm{i}}$ & $7.4^{\mathrm{i}}$ & $795^{i}$ \\
\hline Chacma baboon & $181^{\mathrm{c}}$ & $2559^{j}$ & $84^{j}$ & $65.0^{j}$ & $20.9^{j}$ & $8.1^{j}$ & $1077^{j}$ \\
\hline
\end{tabular}

a Present study

bElston et al., 2006a

c Stephan et al., 1981

dElston et al., $2005 \mathrm{c}$

e Elston et al., 2005b

${ }^{f}$ Elston et al., 1999

g Elston, $2003 b$

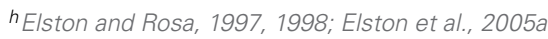

iElston et al., 2005d

jElston et al., $2005 \mathrm{e}$ 

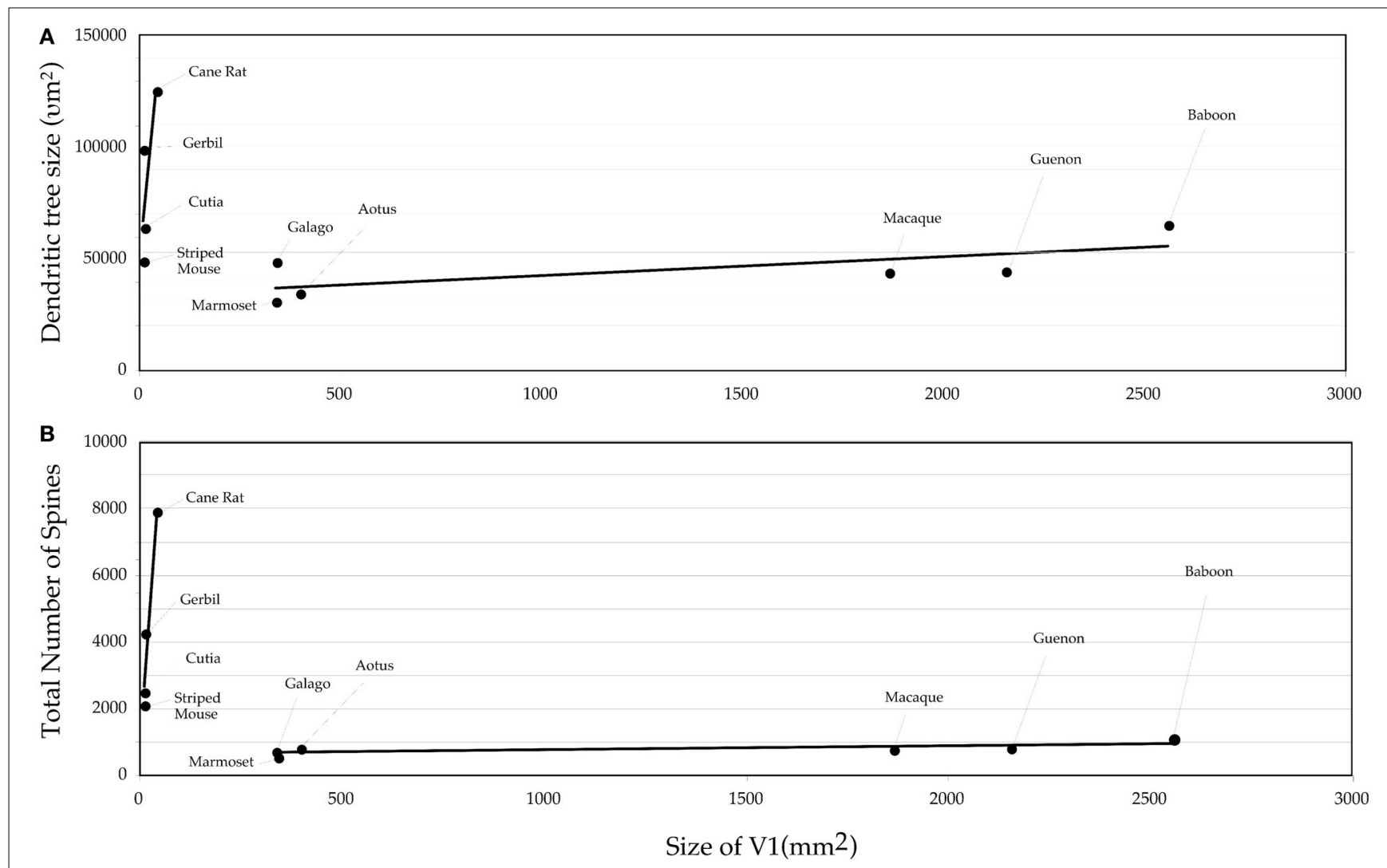

FIGURE 4 | Graph of the (A) size and (B) the number of dendritic spines in the "average" pyramidal cell vs. the size of the primary visual area (V1) in the cane rat, bushvelt gerbil, striped mouse, agouti, tree shrew, galago, marmoset monkey, owl monkey, guenon (vervet monkey), macaque monkey, and baboon. Separate trend lines (linear regressions) are illustrated for the rodent and primate data. see Warton et al., 2006). It appears likely that different principles determine pyramidal cell structure in V1 of adult rodents and primates, which cannot be attributed to a simple cross-species scaling algorithm. For example, the basal dendritic field areas of pyramidal cells in $\mathrm{V} 1$ of the greater cane rat are, on average, nearly three times larger than those in the macaque monkey, while the brain of the greater cane rat weighs only $20 \%$ that of the macaque monkey and the size of V1 in the cane rat is $2.5 \%$ that of the macaque. Moreover, pyramidal neurons in V1 of all rodents included for analyses have considerably more spines in their dendritic trees than those in V1 of primates: those in the cane rat have more than 10 times the number of spines than do those in the macaque monkey (Figure 6).

Previously it has been suggested that the dendritic trees of pyramidal cells may be larger and more branched, may be smaller and less branched, or be the same, in species with increasingly larger cerebral cortex (see Figure 37 of Elston, 2007). Moreover, it has been speculated that pyramidal neurons in species characterized by similar sized cortices may have dramatically different dendritic trees (see Ringo, 1991; Elston, 2007, for reviews). The present data confirms that, within V1, pyramidal cells in small brains may be larger and more branched and more spinous than those in large brains. It then becomes natural to ask why the relationship between the size/branching structure of pyramidal cells and the size of V1/the brain in rodents differs so dramatically to that in primates.

One possibility is that the data reflect fundamentally different evolutionary principles in rodents and primates (see Gould, 2002; Manger, 2005a,b for reviews). In V1 in rodents, the larger the brain, the larger, more branched, and more spinous the neurons, as compared with smaller brains. In V1 in primates, the size, branching complexity, and number of spines is relatively constant among pyramidal cells irrespective of the size of the brain. It could be argued, for example, that mechanisms that determine cortical size and neuron size are linked in rodents but not primates. However, if this were a feature of phylogeny one might expect to see a similar trend in other cortical areas. There are as yet no comparative data of this type in sensory areas such as somatosensory cortex or auditory cortex. There are, however, data sampled from gPFC in primates of different sized brains. In gPFC in primates, pyramidal cells are progressively larger, more branched and more spinous in species with increasing size of the granular PFC (Elston et al., 2006b). That is to say, while there is little difference in the size of neurons in $\mathrm{V} 1$ of primates with different sized primary visual corticies, there is a dramatic parallel in the granular PFC. Thus, presently available data suggests that the different trends observed here in $\mathrm{V} 1$ of rodents and primates is not attributable to phylogeny, or if they are, there is no one rule to 


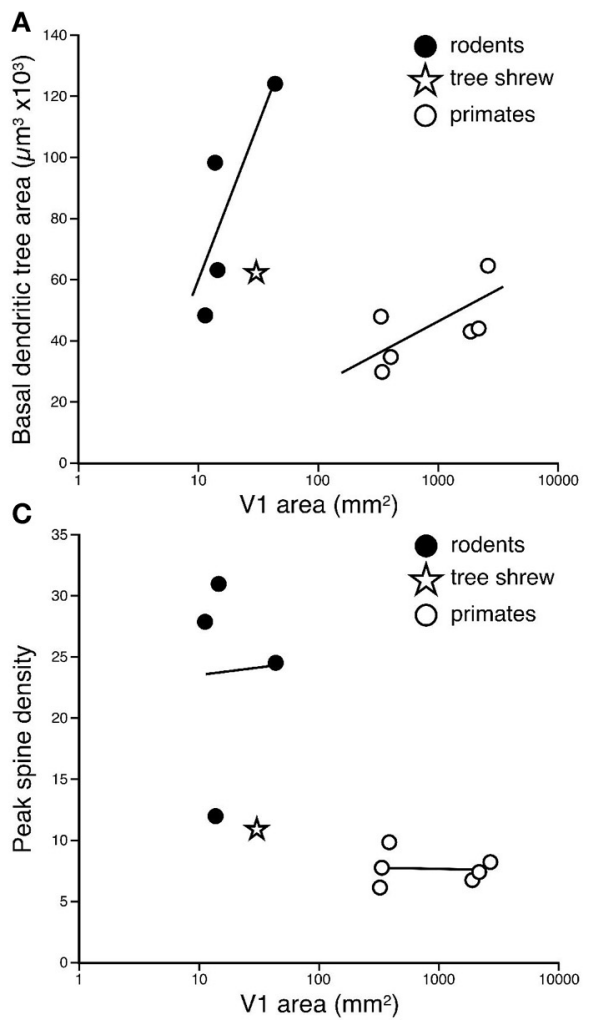

FIGURE 5 | Logarhythmic plots of the basal dendritic tree areas (A), peak branching complexity (B), peak spine density (C), and total spine number (D) of the "average" pyramidal cell against the size of the primary visual area (V1) in the cane rat, bushveld gerbil, four-striped mouse, agouti, tree shrew, galago, marmoset monkey, owl monkey, guenon (vervet monkey), macaque monkey, and baboon (see Table 1 for raw data and sources of

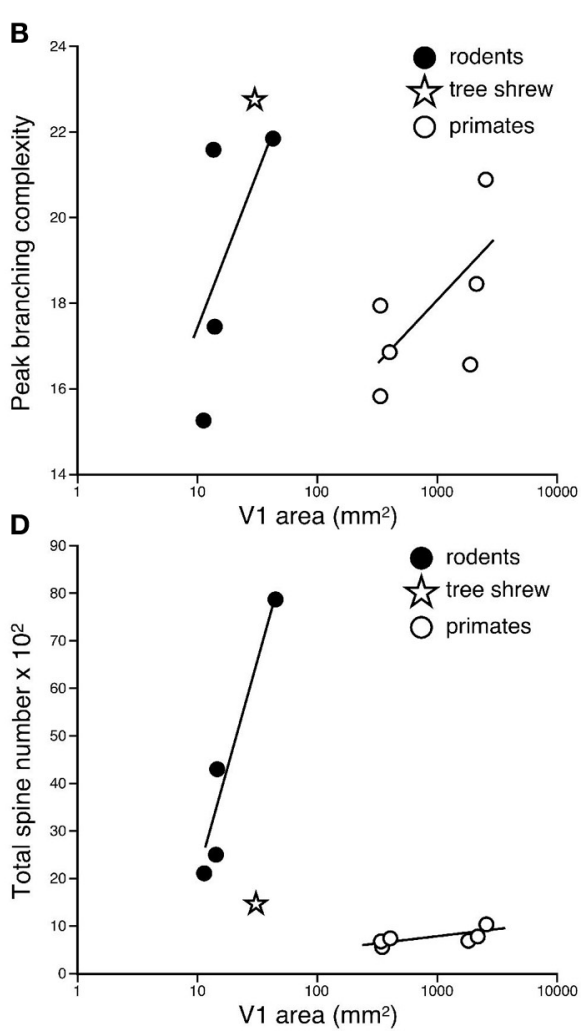

data). Separate trend lines (linear regressions) are illustrated for the rodent and primate data. Tests for differences in slopes and elevations (using the software SMATR ver 2.0, Warton et al., 2006) between the linear correlations of the rodent and primate data were all statistically significant $(p<0.05)$. Note that in all comparisons, the data for the tree shrew is more closely aligned with the rodent data, rather than the primate data. fit all cortical areas. Further data are required in other homologous cortical regions in species of both Orders to provide further clarify.

As each spine receives at least one excitatory input (DeFelipe et al., 1988; Petralia et al., 1994a,b,c; Arellano et al., 2007), the different trends between mammalian orders likely reflect different patterns of connectivity, circuit complexity, functional capacity, and behavioral outcomes (see Nieuwenhuys, 1994; Kaas, 2000; Gould, 2002; Chklovskii et al., 2004; Manger, 2005a; Elston, 2007; Spruston, 2008, for reviews). In future it will be worthwhile to study pyramidal cells in V1 of large brained rodents such as Paca and Capybara, and quantify neuron density (e.g., Collins et al., 2010; Herculano-Houzel et al., 2011; Ribeiro et al., 2013; Young et al., 2013) to provide further bases for comparison (see Manger et al., 2008, for a review). It will also be interesting to compare spine morphologies among species to provide more information of functional specializations between the two orders (e.g., Benavides-Piccione et al., 2003).

The observed differences in pyramidal cell structure detailed here between primates and rodents may also reflect a difference in the processing of visual information in V1 of the different species. For example, the tangential area occupied by the "average" dendritic tree of layer III pyramidal cells in V1 of the adult cane rat is nearly three times the size of that in the adult macaque monkey (Figure 6). Differences in the size, branching structure and spine density result in a more than 10-fold difference in the estimate of the total number of spines, putative excitatory inputs, in the basal dendritic tree of the "average" layer III pyramidal cell between the two species. As V1 in the adult macaque is, on average, more than 40 times the size of V1 in the adult cane rat., the dendritic trees of cells in the adult cane rat sample a portion of the visuotopic field approximately 120 times larger than do those at the same eccentricity in the adult monkey (i.e., the dendritic trees of cells in the cane rat are three times larger than those in the macaque and sample from a visuotopic representation 40 times smaller than do those in the macaque). Thus, 120 cells are required in the macaque monkey V1 to achieve the spatial coverage of a single cell in the cane rat (Figure 6). One hundred and twenty cells in the adult macaque V1 have, on average, a sum total of more than 88,000 spines $(120 \times 743)$, being more than 110 times the number of spines in an individual cell in the adult cane rat. Although this is a fairly simplistic calculation, and doesn't take into account features such as branching density (space filling), neuron density, and reciprocal connectivity, 


\section{Absolute size of the dendritic trees}
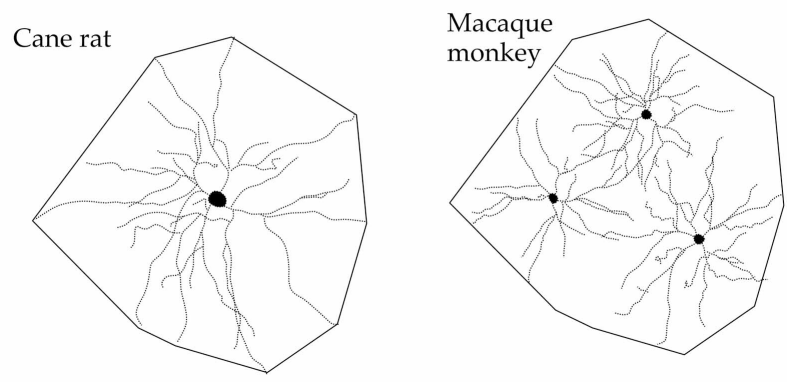

\section{Number of dendritic spines}
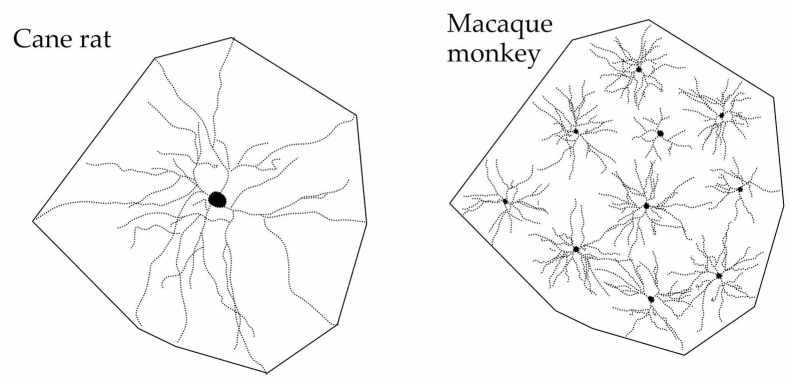

\section{Portion of visuotopic representation}
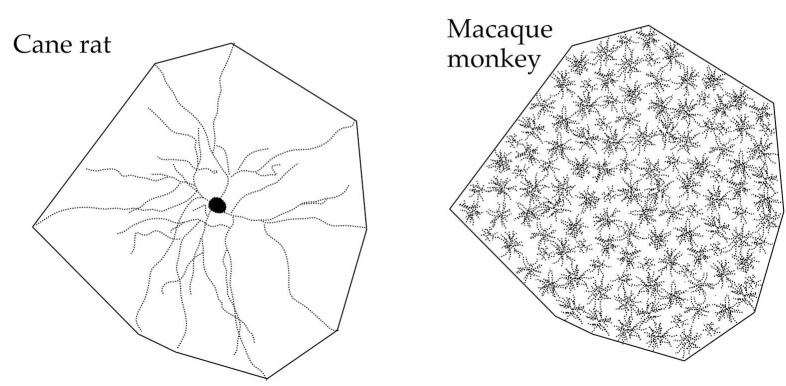

FIGURE 6 | Line drawings, not drawn to scale, illustrating (top) the "average" dendritic tree of layer III pyramidal cells in V1 of the adult cane rat is nearly three times the size of that in the adult macaque monkey. Differences in the size, branching structure, and spine density result in a more than 10-fold difference (middle) in the estimate of the total number of spines, putative excitatory inputs, in the basal dendritic tree of the "average" layer III pyramidal cell between the two species. As $\mathrm{V} 1$ in the adult macaque is, on average, more than 40 times the size of $V 1$ in the adult cane rat (bottom), the dendritic trees of cells in the adult cane rat sample a portion of the visuotopic field approximately 120 times larger than do those in the adult monkey (i.e., the dendritic trees of cells in the cane rat are three times larger than those in the macaque and sample from a visuotopic representation 40 times smaller than do those in the macaque). Thus, 120 cells are required in the macaque monkey $\mathrm{V} 1$ to achieve the spatial coverage of a single cell in the cane rat. One hundred and twenty cells in the adult macaque $\mathrm{V} 1$ have, on average, a sum total of more than 88,000 spines $(120 \times 743)$, being more than 110 times the number of spines in an individual cell in the adult cane rat. Although this is a fairly simplistic calculation, and doesn't take into account features such as branching density (space filling), neuron density, and reciprocal connectivity, it does, we hope, reveal that cortical circuitry in V1 of the cane rat is quantifiably different to that in the macaque monkey. it does, we hope, reveal that cortical circuitry in V1 of the cane rat is quantifiably different to that in the macaque monkey. The data suggest high fidelity, high acquity processing in $\mathrm{V} 1$ of the macaque relative to that of the rat.

Furthermore, in primates it is well known that several, 35 or more, topographically organized visual cortex areas are present (Felleman and Van Essen, 1991). In rodents the number of visual cortical areas appears to be far less, but the exact number of cortical areas in rodents is a matter of ongoing debate, with arguments for between 3 and 11 areas being forwarded (e.g., Montero, 1993; Rumberger et al., 2001). Despite the contention as to the number of visual areas in rodents, it is clear that there are significantly fewer visual cortical areas in rodents than primates. One may speculate that the task of receiving and integrating visual information in primates may be done in more cortical areas than in rodents, with areas comprising increasing circuit complexity allowing for specialized integration of different visual input. Accordingly, by virtue of the fewer visual areas in the rodent, the neurons in V1 undertake a greater computational task than in the primates, therefore requiring greater sampling of the visual input as evidenced by the larger basal dendritic trees, and more spines, and more local processing within the highly branched dendritic trees. However, this idea requires further testing given the potential number of confounds.

The present physiological data suggests that single unit responses to visual stimuli in rodents are not that different to those in primates (Tiao and Blakemore, 1976; Mangini and Pearlman, 1980; Metin et al., 1988; Girman et al., 1999; Schuett et al., 2002; Van Hooser et al., 2005). However, in view of parallels demonstrated between pyramidal cells structure and function in studies in the developing and aging cortex (McCormick and Prince, 1987; Kasper et al., 1994; Metherate and Aramakis, 1999; Zhang, 2004; Oswald and Reyes, 2008), and between different cortical areas (e.g., Amatrudo et al., 2012; see also Funahashi et al., 1993; Miller et al., 1993, 1996), it is parsimonious suspect that differences in pyramidal cell structure in V1 of rodents and primates are paralleled by differences in their electrophysiological properties (see Elston, 2002, 2003a; Jacobs and Scheibel, 2002; Spruston, 2008, for reviews). We hope the present morphological data will inspire new experiments in which a standardized methodological approach is applied to a comparative study of the electrophysiological properties of pyramidal cells, such as resting membrane potentials, membrane time constant, depolarizing sag, duration of individual action potentials, and spike-frequency adaptation, in V1 of rodents and primates. This avenue of research may lead to interesting insights into how very different cerebral cortices may extract similar information from the visual scene, or, alternatively, reveal previously undescribed differences in neuronal response properties in $\mathrm{V} 1$ in rodents and primates.

\section{CONCLUSIONS}

Pyramidal cell structure in rodent V1 differs considerably to that in primates. In rodents, pyramidal cells are progressively larger, more branched and more spinous in species with progressively larger brains. In primates, there is relatively little difference in 
the size, branching structure, and number of spines in pyramidal cells in species with progressively larger brains. The two distinct trends observed in rodents and primates cannot reasonably be attributed a single scaling rule or allometric equation, but appear to reflect fundamentally different modes of cortical organization. As more data becomes available it is becoming increasingly clearer that not only should principles of cortical microcircuitry not be generalized across cortical areas within a given species, but they should not be generalized across species for a given cortical area.

\section{ACKNOWLEDGMENTS}

Supported by grants from the JS McDonnell Foundation (Guy N. Elston), the Australian National Health and Medical Research Council (Guy N. Elston) the South African National Research Foundation (Paul Manger). The authors would like to thank Jason Hemingway and Muhammad Spocter for their generous assistance with statistical analyses presented in the current paper. Address correspondence and reprint requests to Guy N. Elston at the Centre for Cognitive Neuroscience, 60b Duke Rd Doonan, Sunshine Coast, QLD 4562, Australia.

\section{REFERENCES}

Amatrudo, J. M., Weaver, C. M., Crimins, J. L., Hof, P. R., Rosene, D. L., and Luebke, J. I. (2012). Influence of highly distinctive structural properties on the excitability of pyramidal neurons in monkey visual and prefrontal cortices. J. Neurosci. 32, 13644-13660. doi: 10.1523/JNEUROSCI.258112.2012

Arellano, J. I., Espinosa, A., Fairen, A., Yuste, R., and DeFelipe, J. (2007). Non-synaptic dendritic spines in neocortex. Neuroscience 145, 464-469. doi: 10.1016/j.neuroscience.2006.12.015

Ballesteros-Yáñez, I., Benavides-Piccione, R., Elston, G. N., Yuste, R., and DeFelipe, J. (2006). Density and morphology of pyramidal cell dendritic spines in the mouse neocortex. Neuroscience 138, 403-409. doi: 10.1016/j.neuroscience.2005.11.038

Benavides-Piccione, R., Ballesteros-Yáñez, I., DeFelipe, J., and Yuste, R. (2003). Cortical area and species differences in dendritic spine morphology. J. Neurocytol. 31, 337-346. doi: 10.1023/A:1024134312173

Benavides-Piccione, R., Hamzei-Sichani, F., Ballesteros-Yanez, I., Defelipe, J., and Yuste, R. (2006). Dendritic size of pyramidal neurons differs among mouse cortical regions. Cereb. Cortex 16, 990-1001. doi: 10.1093/cercor/bhj041

Bianchi, S., Stimpson, C. D., Bauernfeind, A. L., Schapiro, S. J., Baze, W. B., McArthur, M. J., et al. (2012). Dendritic morphology of pyramidal neurons in the chimpanzee neocortex: regional specializations and comparison to humans. Cereb. Cortex 10, 2429-2436. doi: 10.1093/cercor/bhs239

Bourgeois, J.-P., Goldman-Rakic, P. S., and Rakic, P. (1994). Synaptogenesis in the prefrontal cortex of rhesus monkeys. Neuroscience 4, 78-96. doi: 10.1093/cercor/4.1.78

Bourgeois, J.-P., and Rakic, P. (1993). Changes of synaptic density in the primary visual cortex of the macaque monkey from fetal to adult stage. J. Neurosci. 13, 2801-2820.

Campi, K., Collins, C. E., Todd, W. D., Kaas, J., and Krubitzer, L. (2011). Comparison of area 17 cellular composition in laboratory and wild-caught rats including diurnal and nocturnal species. Brain Behav. Evol. 77, 116-130. doi: $10.1159 / 000324862$

Chklovskii, D. B., Mel, B. W., and Svoboda, K. (2004). Cortical rewiring and information storage. Nature 431, 782-788. doi: 10.1038/nature03012

Collins, C. E., Airey, D. C., Young, N. A., Leitch, D. B., and Kaas, J. H. (2010). Neuron densities vary across and within cortical areas in primates. Proc. Natl. Acad. Sci. U.S.A. 107, 15927-15932. doi: 10.1073/pnas.1010356107

Defelipe, J. (2011). The evolution of the brain, the human nature of cortical circuits, and intellectual creativity. Front. Neuroanat. 5:29. doi: $10.3389 /$ fnana.2011.00029
DeFelipe, J., Conti, F., Van Eyck, S. L., and Manzoni, T. (1988). Demonstration of glutamate-positive axon terminals forming asymmetric synapses in cat neocortex. Brain Res. 455, 162-165. doi: 10.1016/0006-8993(88) 90127-8

Eayrs, J. T., and Goodhead, B. (1959). Postnatal development of the cerebral cortex in the rat. J. Anat. 93, 385-402.

Elston, G. N. (2001). Interlaminar differences in the pyramidal cell phenotype in cortical areas $7 \mathrm{~m}$ and STP (the superior temporal polysensory area) of the macaque monkey. Exp. Brain Res. 138, 141-152. doi: 10.1007/ s002210100705

Elston, G. N. (2002). Cortical heterogeneity: implications for visual processing and polysensory integration. J. Neurocytol. 31, 317-335. doi: 10.1023/A:1024182228103

Elston, G. N. (2003a). Cortex, cognition and the cell: new insights into the pyramidal neuron and prefrontal function. Cereb. Cortex 13, 1124-1138. doi: $10.1093 /$ cercor/bhg093

Elston, G. N. (2003b). Pyramidal cell heterogeneity in the visual cortex of the nocturnal New World owl monkey (Aotus trivirgatus). Neuroscience 117, 213-219. doi: 10.1016/S0306-4522(02)00806-0

Elston, G. N. (2007). "Specializations in pyramidal cell structure during primate evolution," in Evolution of Nervous Systems, eds J. H. Kaas and T. M. Preuss (Oxford: Academic Press), 191-242.

Elston, G. N., Benavides-Piccione, R., and DeFelipe, J. (2005a). A study of pyramidal cell structure in the cingulate cortex of the macaque monkey with comparative notes on inferotemporal and primary visual cortex. Cereb. Cortex 15, 64-73. doi: 10.1093/cercor/bhh109

Elston, G. N., Elston, A., Kaas, J., and Casagrande, V. A. (2005b). Regional specialization in pyramidal cell structure in the visual cortex of the galago. An intracellular injection study with comparative notes on New World and Old World monkeys. Brain Behav. Evol. 66, 10-21. doi: 10.1159/ 000085044

Elston, G. N., Elston, A., Casagrande, V. A., and Kaas, J. (2005c). Areal specialization in pyramidal cell structure in the visual cortex of the tree shrew: a new twist revealed in the evolution of cortical circuitry. Exp. Brain Res. 163, 13-20. doi: 10.1007/s00221-004-2131-7

Elston, G. N., Benavides-Piccione, R., Elston, A., Manger, P., and DeFelipe, J. (2005d). Pyramidal cell specialization in the occipitotemporal cortex of the vervet monkey (Cercopithecus pygerythrus). Neuroreport 16, 967-970. doi: 10.1097/00001756-200506210-00017

Elston, G. N., Benavides-Piccione, R., Elston, A., DeFelipe, J., and Manger, P. (2005e). Pyramidal cell specialization in the occipitotemporal cortex of the Chacma baboon (Papio ursinus). Exp. Brain Res. 167, 496-503. doi: 10.1007/s00221-005-0057-3

Elston, G. N., and DeFelipe, J. (2002). "Spine distribution in neocortical pyramidal cells: a common organizational principle across species," in Progress in Brain Research, eds E. C. Azmitia, J. DeFelipe, E. G. Jones, P. Rakic, and C. E. Ribak (Amsterdam: Elsevier), 109-133.

Elston, G. N., Elston, A., Aurelio-Freire, M., Gomse Leal, W., and Picanço Diniz, C. W. (2006a). Area specific specialization of pyramidal cell structure in the visual cortex of the South American rodent, Dasyprocto aguti. Exp. Brain Res. 1106, 99-110. doi: 10.1016/j.brainres.2006. 05.100

Elston, G. N., Benavides-Piccione, R., Elston, A. B. Z., DeFelipe, J., Manger, P., Casagrande, V., et al. (2006b). Evolutionary specializations in the granular prefrontal cortex of primates subserve different cognitive styles. Anat. Rec. 288A, 26-35. doi: 10.1002/ar.a.20278

Elston, G. N., Elston, A., Aurelio-Freire, M., Gomes Leal, W., Amaral Dias, I., Pereira Jr, A., et al. (2006c). Specialization of pyramidal cell structure in the visual areas V1, V2 and V3 of the South American rodent, Dasyprocta primnolopha. Brain Res. 1106, 99-110. doi: 10.1016/j.brainres.2006. 05.100

Elston, G. N., Oga, T., Okamoto, T., and Fujita, I. (2010). Spinogenesis and pruning from early visual onset to adulthood: an intracellular injection study of layer III pyramidal cells in the ventral visual cortical pathway of the macaque monkey. Cereb. Cortex 20, 1398-1408. doi: 10.1093/cercor/ bhp 203

Elston, G. N., Pow, D. V., and Calford, M. B. (1997). Neuronal composition and morphology in layer IV of two vibrissal barrel subfields of rat cortex. Cereb. Cortex 7, 422-431. doi: 10.1093/cercor/7.5.422 
Elston, G. N., and Rosa, M. G. P. (1997). The occipitoparietal pathway of the macaque monkey: comparison of pyramidal cell morphology in layer III of functionally related cortical visual areas. Cereb. Cortex 7, 432-452. doi: 10.1093/cercor/7.5.432

Elston, G. N., and Rosa, M. G. P. (1998). Morphological variation of layer III pyramidal neurones in the occipitotemporal pathway of the macaque monkey visual cortex. Cereb. Cortex 8, 278-294. doi: 10.1093/cercor/8.3.278

Elston, G. N., Tweedale, R., and Rosa, M. G. P. (1999). Cellular heterogeneity in cerebral cortex. A study of the morphology of pyramidal neurones in visual areas of the marmoset monkey. J. Comp. Neurol. 415, 33-51. doi: $\quad$ 10.1002/(SICI) 1096-9861(19991206)415:1\%3C33::AID-CNE3\%3E3. $0 . \mathrm{CO} ; 2-\mathrm{M}$

Felleman, D., and Van Essen, D. (1991). Distributed hierarchical processing in the primate cerebral cortex. Cereb. Cortex 1, 1-47. doi: 10.1093/cercor/1.1.1

Freire, M. A. M., Rocha, E. G., Oliveira, J. L. F., Guimarães, J. S., Silveira, L. C., Elston, G. N., et al. (2010). Morphological variability of NADPH diaphorase neurons across areas V1, V2 and V3 of common agouti. Brain Res. 1318, 52-63. doi: 10.1016/j.brainres.2009.12.045

Funahashi, S., Chafee, M. V., and Goldman-Rakic, P. S. (1993). Prefrontal activity in rhesus monkeys performing a delayed anti-saccad task. Nature 365, 753-756. doi: $10.1038 / 365753 \mathrm{a} 0$

Girman, S. V., Sauve, Y., and Lund, R. D. (1999). Receptive field properties of single neurons in rat primary visual cortex. J. Neurophysiol. 82, 301-311.

Gould, S. J. (2002). The Structure of Evolutionary Theory. Cambridge, MA: Harvard University Press.

Herculano-Houzel, S., Ribeiro, P., Campos, L., Valotta da Silva, A., Torres, L. B., Catania, K. C., et al. (2011). Updated neuronal scaling rules for the brains of Glires (rodents/lagomorphs). Brain Behav. Evol. 78, 302-314. doi: $10.1159 / 000330825$

Hubel, D. H., and Wiesel, T. N. (1968). Receptive fields and functional architecture of monkey striate cortex. J. Physiol. 195, 215-243.

Jacobs, B., and Scheibel, A. B. (2002). "Regional dendritic variation in primate cortical pyramidal cells," in Cortical Areas: Unity and Diversity, eds A. Schüz and R. Miller (London: Taylor and Francis), 111-131. doi: 10.1201/9780203299296.pt2

Kaas, J. (2000). Why is brain size so important: design problems and solutions as neocortex gets bigger or smaller. Brain Mind 1, 7-23. doi: 10.1023/A:1010028405318

Kasper, E. M., Larkman, A. U., Lübke, J., and Blakemore, C. (1994). Pyramidal neurons in layer 5 of the rat visual cortex. II. Development of electrophysiological properties. J. Comp. Neurol. 339, 475-494. doi: 10.1002/cne. 903390403

Lund, J. S., Yoshioka, T., and Levitt, J. B. (1993). Comparison of intrinsic connectivity in different areas of macaque monkey cerebral cortex. Cereb. Cortex 3 , 148-162. doi: 10.1093/cercor/3.2.148

Manger, P. R. (2005a). Establishing order at the systems level in mammalian brain evolution. Brain Res. Bull. 66, 282-289. doi: 10.1016/j.brainresbull.2005. 05.002

Manger, P. R. (2005b). "Evolution of the modern human brain: P.V. Tobias' hominization, Ockham's razor, and Asimov's elephant," in Voyages in Science, Essays by South African Anatomists in Honour of Phillip V. Tobias's 80th Birthday, eds G. Strklaj, N. Pather, and B. Kramer (Pretoria: Content Solutions), 51-84.

Manger, P. R., Cort, J., Ebrahim, N., Goodman, A., Henning, J., Karolia, M., et al. (2008). Is 21st century neuroscience too focussed on the rat/mouse model of brain function and dysfunction? Front. Neuroanat. 2:5. doi: 10.3389/neuro.05.005.2008

Mangini, N. J., and Pearlman, A. L. (1980). Laminar distribution of receptive field properties in the primary visual cortex of the mouse. J. Comp. Neurol. 193, 203-222. doi: $10.1002 /$ cne.901930114

McCormick, D. A., and Prince, D. A. (1987). Post-natal development of electrophysiological properties of rat cerebral cortical pyramidal neurones. J. Physiol. $393,743-762$.

Metherate, R., and Aramakis, V. B. (1999). Intrinsic electrophysiology of neurons in thalamorecipient layers of developing rat auditory cortex. Brain Res. Dev. Brain Res. 115, 131-144. doi: 10.1016/S0165-3806(99) 00058-9

Metin, C., Godement, P., and Imbert, M. (1988). The primary visual cortex in the mouse: receptive field properties and functional organization. Exp. Brain Res. 69, 594-612. doi: 10.1007/BF00247312
Miller, E. K., Erickson, C. A., and Desimone, R. (1996). Neural mechanisms of visual working memory in prefrontal cortex of the macaque. J. Neurosci. 16, 5154-5167.

Miller, E. K., Li, L., and Desimone, R. (1993). Activity of neurons in anterior inferior temporal cortex during a short-term memory task. J. Neurosci. 13, $1460-1478$.

Montero, V. M. (1993). Retinotopy of cortical connections between the straite cortex and extrastriate visual areas in the rat. Exp. Brain Res. 94, 1-15. doi: 10.1007/BF00230466

Nieuwenhuys, R. (1994). The Neocortex. An overview of its evolutionary development, structural organization and synaptology. Anat. Embrol. 190, 307-337. doi: 10.1007/BF00187291

Oga, T., Aoi, H., Sasaki, T., Fujita, I., and Ichinohe, N. (2013). Postnatal development of layer III pyramidal cells in the primary visual, inferior temporal, and prefrontal cortices of the marmoset. Front. Neural Circuits 7:31. doi: 10.3389/fncir.2013.00031

Oswald, A.-M., and Reyes, A. D. (2008). Maturation of intrinsic and synaptic properties of layer $2 / 3$ pyramidal neurons in mouse auditory cortex. J. Neurophysiol. 99, 2998-3008. doi: 10.1152/jn.01160.2007

Petralia, R. S., Yokotani, N., and Wenthold, R. J. (1994a). Light and electron microscope distribution of the NMDA receptor subunit NMDAR1 in the rat nervous system using a selective antipeptide antibody. J. Neurosci. 14, 667-696.

Petralia, R. S., Wang, Y. X., and Wenthold, R. J. (1994b). The NMDA receptor subunits NR2A and NR2B show histological and ultrastructural localization patterns similar to those of NR1. J. Neurosci. 14, 6102-6120.

Petralia, R. S., Wang, Y.-X., and Wenthold, R. J. (1994c). Histological and ultrastructural localization of kainate receptor subunits, KA2 and GluR6/7, in the rat nervous system using selective antipeptide antibodies. J. Comp. Neurol. 349, 85-110. doi: 10.1002/cne.903490107

Rakic, P., Bourgeois, J.-P., Eckenhoff, M. F., Zecevic, N., and Goldman-Rakic, P. S. (1986). Concurrent overproduction of synapses in diverse regions of the primate cerebral cortex. Science 232, 232-235. doi: 10.1126/science. 3952506

Ribeiro, P. F., Ventura-Antunes, L., Gabi, M., Mota, B., Grinberg, L. T., Farfel, J. M., et al. (2013). The human cerebral cortex is neither one nor many: neuronal distribution reveals two quantitatively different zones in the gray matter, three in the white matter, and explains local variations in cortical folding. Front. Neuroanat. 7:28. doi: 10.3389/fnana.2013.00028

Ringo, J. L. (1991). Neuronal interconnection as a function of brain size. Brain Behav. Evol. 38, 1-6. doi: 10.1159/000114375

Rosa, M. G., and Krubitzer, L. A. (1999). The evolution of visual cortex: where is V2? Trends Neurosci. 22, 242-248. doi: 10.1016/S0166-2236(99) 01398-3

Rumberger, A., Tyler, C. J., and Lund, J. S. (2001). Intra- and inter-areal connections between the primary visual cortex V1 and the area immediately surrounding V1 in the rat. Neuroscience 102, 35-52. doi: 10.1016/S0306-4522(00) 00475-9

Schuett, S., Bonhoeffer, T., and Hubener, M. (2002). Mapping retinotopic structure in mouse visual cortex with optical imaging. J. Neurosci. 22, 6549-6559.

Sholl, D. A. (1953). Dendritic organization in the neurons of the visual and motor cortices of the cat. J. Anat. 87, 387-406.

Spruston, N. (2008). Pyramidal neurons: dendritic structure and synaptic integration. Nat. Rev. Neurosci. 9, 206-221. doi: 10.1038/nrn2286

Stephan, H., Frahm, H., and Baron, G. (1981). New and revised data on volumes of brain structures in insectivores and primates. Folia Primatol. 35, 1-29. doi: $10.1159 / 000155963$

Tiao, Y. C., and Blakemore, C. (1976). Functional organization in the visual cortex of the golden hamster. J. Comp. Neurol. 168, 459-481. doi: $10.1002 /$ cne. 901680403

Valverde, F. (1967). Apical dendritic spines of the visual cortex and light deprivation in the mouse. Exp. Brain Res. 3, 337-352. doi: 10.1007/BF00237559

Van Hooser, S. D., Helmel, J. A. F., Chung, S., Nelson, S. B., and Toth, L. J. (2005). Orientation selectivity without orientation maps in visual cortex of a highly visual mammal. J. Neurosci. 25, 19-28. doi: 10.1523/JNEUROSCI.404204.2005

Warton, D. I., Wright, I. J., Falster, D. S., and Westoby, M. (2006). Bivariate line-fitting methods for allometry. Biol. Rev. 81, 259-291. doi: $10.1017 / S 1464793106007007$ 
Wong-Riley, M. (1979). Changes in the visual system of monocularly sutured or enucleated cats demonstrable with cytochrome oxidase histochemistry. Brain Res. 171, 11-28. doi: 10.1016/0006-8993(79)90728-5

Young, N. A., Collins, C. E., and Kaas, J. H. (2013). Cell and neuron densities in the primary motor cortex of primates. Front. Neural Circuits 7:30. doi: 10.3389/fncir.2013.00030

Zhang, Z. W. (2004). Maturation of layer V pyramidal neurons in the rat prefrontal cortex: intrinsic properties and synaptic function. J. Neurophysiol. 91, 1171-1182. doi: 10.1152/jn.00855.2003

Conflict of Interest Statement: The authors declare that the research was conducted in the absence of any commercial or financial relationships that could be construed as a potential conflict of interest.
Received: 17 September 2013; paper pending published: 30 November 2013; accepted: 20 January 2014; published online: 10 February 2014.

Citation: Elston GN and Manger P (2014) Pyramidal cells in V1 of African rodents are bigger, more branched and more spiny than those in primates. Front. Neuroanat. 8:4. doi: 10.3389/fnana.2014.00004

This article was submitted to the journal Frontiers in Neuroanatomy.

Copyright (c) 2014 Elston and Manger. This is an open-access article distributed under the terms of the Creative Commons Attribution License (CC BY). The use, distribution or reproduction in other forums is permitted, provided the original author(s) or licensor are credited and that the original publication in this journal is cited, in accordance with accepted academic practice. No use, distribution or reproduction is permitted which does not comply with these terms. 